\title{
A study of pathway of care among persons with mental illness attending a tertiary care centre in Hyderabad
}

\author{
Divya Meghana Sreevaram¹, M Vijay Kumar ${ }^{2}$, S Sireesha Srinivasa Rao ${ }^{3 *}$ \\ ${ }^{1}$ Junior Resident, ${ }^{2}$ Senior Resident, ${ }^{3}$ Professor and Deputy Superintendent, Dept. of Psychiatry, Institute of Mental Health, Osmania \\ Medical College, Hyderabad, Telangana, India
}

*Corresponding Author: S Sireesha Srinivasa Rao

Email: s283572@gmail.com

\begin{abstract}
Background: Persons with mental illness usually do not visit the mental health facility first. Instead they approach faith healers and other alternative systems. Only when the condition becomes worse, do they seek psychiatrist consultation leading to delay in treatment.

Materials and Methods: A cross sectional study was conducted to understand the pathway of care adopted by persons with mental illness and its relationship with sociodemographic variables. In our study population, 250 patients visiting a psychiatric outpatient department of a tertiary care hospital were interviewed on a semi structured questionnaire for various services contacted by them for their mental health problems. Data was analysed using SPSS version 22.

Results: The initial study sample included 258 patients, out of which 8 were excluded because of exclusion criteria. The final study sample was 250 . The mean age of sample was 35.92yrs. There were 137 males and 113 females. Our study sample comprised of $66.8 \%$ aged between 20 to 40 years, $54.8 \%$ male, $57.2 \%$ were married, $67.6 \%$ were unemployed and $75.2 \%$ earn below 10000 rupees. In illness variables, $32.0 \%$ of study subjects had duration of illness 1 to 5 years, 36.8\% subjects were having schizophrenia followed by mood disorders [22.8\%]. $28.4 \%$ of study sample (71 out of 250) did not consult psychiatrist at all before coming to tertiary care centre out of which $8.8 \%$ consulted faith healers. Rest $71.66 \%$ of study sample consulted general practitioners, general physicians, neurologists and ayurvedic unani homeopathic doctors. Reasons given by patient's family members for not consulting psychiatrists were ignorance about illness, financial problems, belief in superstitions, lack of availability of mental health services and stigma towards mental illness.

Socio demographic factors significantly associated with delay in first consultation to psychiatrist were found to be $20-40 \mathrm{yrs}$ of age $(\mathrm{p}=0.000)$, female gender (0.031), illiterate (0.025), unemployment $(0.001)$, income $<10,000(0.014)$, distance $>100 \mathrm{kms}(0.019)$ and diagnosis of schizophrenia(0.000).

Conclusion: Patients with mental illness seek help from nonpsychiatric physicians, faith healers, traditional, alternative systems due to lack of awareness about treatment services, long distances and due to fear of stigma about illness. It is important to sensitize general practitioners about early identification, management and referral of psychiatric disorders.
\end{abstract}

Keywords: Pathway of care, Pathway of care in people with mental illness.

\section{Introduction}

Mental illnesses are commonly associated with higher disability and burden than many physical illnesses. ${ }^{1}$ People who have not previously received mental health services may be particularly reluctant to recognize their need for treatment and establish treatment contact. ${ }^{2}$ Mental illnesses are often accompanied by a lack of awareness and social stigma, which leads patients and their families to seek alternative service providers. ${ }^{3}$ Other reasons like non availability of mental health professionals, superstitions associated with mental disorders, unwillingness or inability of families to care for persons with mental illness, care giver education also adds to delay in psychiatric consultation. The pathway a person with psychiatric problem adopts to reach appropriate treatment/ care is termed as pathway of care. ${ }^{1}$ Even in developed countries like USA, Canada, Italy, Netherlands one third of people with mental disorder don't seek treatment from mental health services, rather approach general practitioners, general physicians and are referred to psychiatrists afterwards. ${ }^{4}$ In India mental health resources are very low compared with high income countries. The facilities for psychiatric treatment are generally available in general hospital psychiatric units, mental hospitals. Apart from this patients may consult non psychiatric physicians, general practitioners, lay counsellors, local religious leaders and traditional faith healers. ${ }^{3-7}$

Different studies on pathway of care have quoted different reasons for seeking help from different resources like, easy accessibility, belief in the system or particular healer and good reputation. They were spending highest amount on non psychiatric physician, lowest expenditure on alternative system of practitioners. Patients who received mood, anxiety disorder were less likely to make first contact with psychiatrist, more likely to visit primary care. Those who were separated or widowed or divorced were significantly associated with longer duration of untreated illness. ${ }^{1,3,8}$

An understanding of the way people with mental illnesses seek care for their illnesses is recognized as important for planning mental health services, organizational training and referral from other sources of health and social care services. ${ }^{9}$ So, this study was conducted to study the delay in duration and reasons, different places where help was taken before attending first psychiatric consultation among patients attending psychiatric OPD of tertiary care hospital.

Aims

1. To study the delay in duration for first psychiatric consultation. 
2. To study the reasons for delay in first psychiatric consultation

3. To study if there is any association between socio demographic factors and illness variables and delay in first consultation

\section{Materials and Methods}

Institutional Ethics committee approval was obtained before conducting the study from Osmania medical college. Permission of authorities were taken before collecting the sample. Data was collected from patients attending the psychiatric OPD of a tertiary care hospital in Hyderabad (Institute of mental health, Erragadda, Hyderabad), Telangana state from October $1^{\text {st }}$ to November $30^{\text {th }} 2019$. Simple random sampling technique was used to select patients. Sample was collected in the out patient department on every Tuesday of the week. Those who are attending the main OPD for the first time, consented for the study and accompanied by a reliable informant were enrolled into the study. Those patients who are excited, did not consent for the study, unable to recollect the delay in duration and reasons for delay and had unreliable informants are excluded from our study. The purpose and objectives of study were explained to patients and their informant in a language which they can understand. Written informed consent was obtained from both patient and attendant before carrying out the study. Consented subjects were entered into the semi structured intake proforma consisting of sociodemographic data, diagnoses as per ICD -10 diagnostic criteria, duration of delay, reasons for delay in first psychiatric consultation were entered. All the data was statistically analysed accordingly to interpret aims and objectives using SPSS version 22. Descriptive statistics were used to tabulate the sociodemographic characteristics and frequencies of clinical characteristics. Chi square test was used to look for association of sociodemographic variables and clinical variables. Level of statistical significance was kept at $<0.05$.

\section{Results}

The initial study sample included 258 patients, out of which 8 were excluded because of exclusion criteria. The final study sample was 250 . The mean age of sample was 35.92yrs. There were 137 males and 113 females.

Table 1: Showing socio demographic data of study population

\begin{tabular}{|l|l|c|c|}
\hline \multirow{3}{*}{ Category } & & $\mathbf{N = 2 5 0}$ & Percentage \\
\hline \multirow{5}{*}{ Gender } & $<20$ years & 6 & $2.4 \%$ \\
\cline { 2 - 4 } & 20 to 40 years & 167 & $66.8 \%$ \\
\cline { 2 - 4 } & 40 to 60 years & 63 & $25.2 \%$ \\
\cline { 2 - 4 } & $>60$ years & 14 & $5.6 \%$ \\
\hline \multirow{3}{*}{ Education } & Male & 137 & $54.8 \%$ \\
\cline { 2 - 4 } & Female & 113 & $45.2 \%$ \\
\hline \multirow{3}{*}{ Employment } & Illiterate & 81 & $32.4 \%$ \\
\cline { 2 - 4 } & Literate & 169 & $67.6 \%$ \\
\hline \multirow{5}{*}{ Income } & Employed & 163 & $34.2 \%$ \\
\cline { 2 - 4 } & Unemployed & 188 & $65.2 \%$ \\
\hline \multirow{3}{*}{ Marital Status } & $<10,000$ & 52 & $75.2 \%$ \\
\cline { 2 - 4 } & 10000 to 20000 & 10 & $20.8 \%$ \\
\cline { 2 - 4 } & $>20000$ & 74 & $5.0 \%$ \\
\cline { 2 - 4 } & Married & 13 & $57.2 \%$ \\
\cline { 2 - 4 } & Unmarried & 17 & $30.8 \%$ \\
\cline { 2 - 4 } & Widowed & & $5.2 \%$ \\
\cline { 2 - 4 } & Separated & & \\
\hline
\end{tabular}

Our study sample comprised of $66.8 \%$ aged between 20 to 40 years, $54.8 \%$ male, $57.2 \%$ were married, $67.6 \%$ were unemployed and $75.2 \%$ earn below 10000 rupees.

Table 2: Showing illness variables

\begin{tabular}{|l|l|c|c|}
\hline Duration of Illness & $<1$ month & 25 & $10 \%$ \\
\cline { 2 - 4 } & 1month to 1 year & 64 & $25.6 \%$ \\
\cline { 2 - 4 } & 1 year to 5 years & 80 & $32.0 \%$ \\
\cline { 2 - 4 } & 5 years to 10 years & 52 & $20.8 \%$ \\
\cline { 2 - 4 } & $>10$ years & 29 & $11.6 \%$ \\
\hline \multirow{5}{*}{ Diagnosis } & Organic & 22 & $8.8 \%$ \\
\cline { 2 - 4 } & Substance & 49 & $19.6 \%$ \\
\cline { 2 - 4 } & Schizophrenia & 92 & $36.8 \%$ \\
\cline { 2 - 4 } & Mood disorders & 57 & $22.8 \%$ \\
\hline
\end{tabular}




\begin{tabular}{|l|l|c|c|}
\cline { 2 - 4 } & Neurotic & 11 & $4.4 \%$ \\
\cline { 2 - 4 } & Others & 19 & $7.6 \%$ \\
\hline First Contact & Faith healer & 88 & $35.2 \%$ \\
\cline { 2 - 4 } & GP & 65 & $26 \%$ \\
\cline { 2 - 4 } & Neurologist & 8 & $3.2 \%$ \\
\cline { 2 - 4 } & Private psychiatrist & 40 & $16 \%$ \\
\cline { 2 - 4 } & Tertiary care centre(IMH) & 49 & $19.6 \%$ \\
\hline
\end{tabular}

In illness variables, $32.0 \%$ of study subjects had duration of illness 1 to 5 year, $36.8 \%$ subjects were having schizophrenia followed by mood disorders [22.8\%]. 35.2\% of study population consulted faith healers for their problems at first instance. $54.8 \%$ before coming to our tertiary care centre (IMH) have not seen any doctors.

Table 3: Showing association between first contact and socio demographic factors

\begin{tabular}{|l|l|c|c|c|c|c|c|c|}
\hline \multirow{2}{*}{ Age } & $\begin{array}{c}\text { Faith } \\
\text { healer }\end{array}$ & $\begin{array}{c}\text { General } \\
\text { practitioners }\end{array}$ & Neurologist & $\begin{array}{c}\text { Private } \\
\text { psychiatrist }\end{array}$ & $\begin{array}{c}\text { Tertiary care } \\
\text { centre(IMH) }\end{array}$ & $\begin{array}{c}\text { Chi } \\
\text { square }\end{array}$ & $\begin{array}{c}\text { P } \\
\text { value }\end{array}$ \\
\cline { 2 - 9 } & $<20$ years & 1 & 2 & 0 & 1 & 2 & 45.060 & 0.000 \\
\cline { 2 - 9 } & 20 to 40 years & 66 & 38 & 4 & 30 & 29 & & \\
\cline { 2 - 9 } & 40 to 60 years & 19 & 18 & 0 & 9 & 17 & & \\
\cline { 2 - 9 } & $>60$ years & 2 & 7 & 4 & 0 & 1 & & \\
\hline Gender & Male & 37 & 38 & 5 & 23 & 34 & 10.06 & 0.031 \\
\hline \multirow{2}{*}{ Literacy } & Female & 51 & 27 & 3 & 17 & 15 & & \\
& Illiterate & 64 & 34 & 4 & 31 & 35 & 11.156 & 0.025 \\
\cline { 2 - 9 } & literate & 24 & 31 & 4 & 9 & 14 & & \\
\hline Employment & Employed & 20 & 20 & 1 & 17 & 27 & 18.529 & 0.001 \\
\hline \multirow{2}{*}{ Income } & unemployed & 68 & 45 & 7 & 21 & 22 & & \\
\hline & $<10000$ & 68 & 54 & 8 & 21 & 37 & 19.23 & 0.014 \\
\hline & 10 to 20000 & 16 & 8 & 0 & 16 & 12 & & \\
\hline
\end{tabular}

Table 4: Showing association between illness variables and first contact

\begin{tabular}{|c|l|c|c|c|c|c|c|c|}
\hline & $\begin{array}{c}\text { Faith } \\
\text { healer }\end{array}$ & $\begin{array}{c}\text { General } \\
\text { practitioners }\end{array}$ & Neurologist & $\begin{array}{c}\text { Private } \\
\text { psychiatrists }\end{array}$ & $\begin{array}{c}\text { Tertiary care } \\
\text { centre(IMH) }\end{array}$ & $\begin{array}{c}\text { Chi } \\
\text { square }\end{array}$ & $\begin{array}{c}\text { P } \\
\text { value }\end{array}$ \\
\hline \multirow{2}{*}{ Distance } & $<100 \mathrm{kms}$ & 42 & 34 & 2 & 23 & 36 & 11.82 & 0.019 \\
\hline & $>100 \mathrm{kms}$ & 46 & 31 & 6 & 17 & 13 & & \\
\hline \multirow{3}{*}{ Diagnosis } & Organic & 0 & 15 & 5 & 0 & 2 & 15.72 & 0.000 \\
\cline { 2 - 9 } & Substance & 2 & 10 & 1 & 6 & 30 & & \\
\cline { 2 - 9 } & Schizophrenia & 55 & 15 & 0 & 16 & 6 & & \\
\cline { 2 - 9 } & Mood disorders & 27 & 13 & 1 & 11 & 5 & & \\
\cline { 2 - 9 } & Neurotic & 1 & 5 & 0 & 3 & 2 & & \\
\cline { 2 - 9 } & Others & 3 & 7 & 1 & 4 & 4 & & \\
\hline
\end{tabular}

Our study found that $75 \%$ of study subjects aged between 20 to $40 \mathrm{yrs}(\mathrm{p}=0.000), 45.1 \%$ are female gender $(\mathrm{p}=0.031)$, $36.1 \%$ low income subjects $(\mathrm{p}=0.014), 72.72 \%$ illiterates $(\mathrm{p}=0.025), 77.27 \%$ unemployed $(\mathrm{p}=0.001), 52.27 \%$ of subjects staying at a distance more than $100 \mathrm{~km}(\mathrm{p}=0.019)$, and $62.5 \%$ carrying diagnosis of schizophrenia $(\mathrm{p}=0.000)$, were significantly associated with delay in first contact with psychiatrist.

Table 5: showing relationship between socio demographic variables and contact before tertiary care centre(IMH)

\begin{tabular}{|c|c|c|c|c|c|c|c|}
\hline & & None & Faith healer & Doctors & Combined & Chi square & P value \\
\hline \multirow[t]{3}{*}{ Gender } & Male & 34 & 8 & 63 & 32 & 9.95 & 0.019 \\
\hline & Female & 15 & 14 & 46 & 38 & & \\
\hline & Total & 49 & 22 & 109 & 70 & & \\
\hline \multirow[t]{3}{*}{ Distance } & $<100 \mathrm{kms}$ & 36 & 15 & 57 & 29 & 13.81 & 0.0003 \\
\hline & $>100 \mathrm{kms}$ & 13 & 7 & 52 & 41 & & \\
\hline & Total & 49 & 22 & 109 & 70 & & \\
\hline \multirow[t]{3}{*}{ employment } & Employed & 27 & 3 & 37 & 18 & 15.87 & 0.001 \\
\hline & Unemployed & 22 & 19 & 70 & 52 & & \\
\hline & Total & 49 & 22 & 107 & 70 & & \\
\hline \multirow[t]{3}{*}{ Diagnosis } & Organic & 2 & 0 & 19 & 1 & 116.67 & 0.000 \\
\hline & Substance & 30 & 1 & 16 & 2 & & \\
\hline & Schizophrenia & 6 & 12 & 29 & 45 & & \\
\hline
\end{tabular}




\begin{tabular}{|l|l|c|c|c|c|c|c|}
\hline & Mood disorders & 5 & 8 & 25 & 19 & & \\
\hline & Neurotic & 2 & 1 & 8 & 0 & & \\
\hline & Others & 4 & 0 & 12 & 3 & & \\
\hline
\end{tabular}

From above table 5 there were 71 subjects out of 250 who didn't seek psychiatrist at all before coming to a tertiary care centre (IMH). They have not consulted any medical professional (28.4\%), out of which $8.8 \%$ consulted only faith healers and $43.6 \%$ approached general practitioners including, AYUSH specialists, neurologists, physicians, rest of the sample consisting mixed approaches to different service providers.

Table 6: Showing reasons given by informants for not consulting psychiatrists

\begin{tabular}{|l|l|c|}
\hline S. No & Reasons & Percentage \\
\hline 1 & Ignorance & 24 \\
\hline 2 & Financial problems & 34 \\
\hline 3 & Superstitions, black magic & 18 \\
\hline 4 & Neighbors advice & 8 \\
\hline 5 & Distance from hospital & 6 \\
\hline 6 & Stigma & 10 \\
\hline
\end{tabular}

Above table shows the reasons given by informants for not consulting psychiatrist as a first resort. Multiple reasons were given like financial limitations (34\%), ignorance (24\%), superstitions (18\%) and others.

Table 7: Showing who suggested our hospital

\begin{tabular}{|l|l|c|}
\hline S.No & Who suggested tertiary care centre & Percentage \\
\hline 1. & Relatives & $39 \%$ \\
\hline 2. & Friends & $18 \%$ \\
\hline 3. & Neighbors & $26 \%$ \\
\hline 4. & Self & $11 \%$ \\
\hline 5. & General practitioners/ faith healers/ others & $6 \%$ \\
\hline
\end{tabular}

Above table shows the responses given by informants of our study subjects regarding various means by which they came to know about a tertiary care centre.

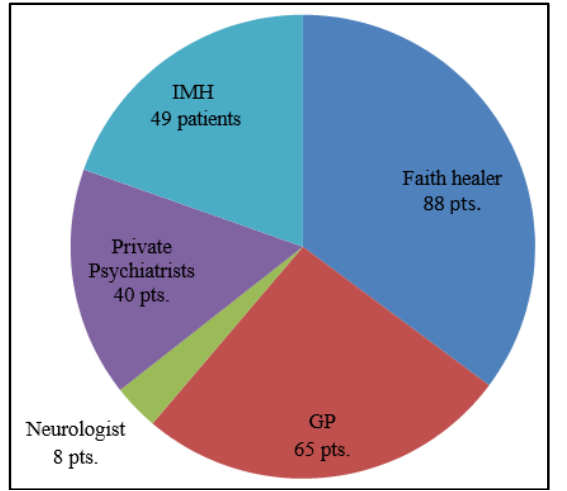

Fig. 1: Showing proportion of patients with whom they made their first contact for their mental illness

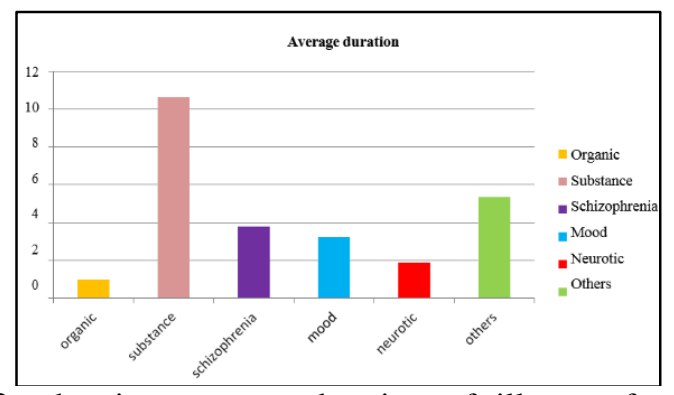

Fig. 2: showing average duration of illness of various disease spectrums at which patients presented to our hospital

\section{Discussion}

The initial study sample was 258 , out of them 8 were excluded as 4 patients had difficulty recalling, 3 patients did not have reliable informant and one patient refused to give consent for participation in our study. In our study, more than $66 \%$ of persons seeking psychiatric care were 20 to 40 years of age, $25.2 \%$ were between 40 to 60 years of age, followed by $5.6 \%$ above 60 years and $2.4 \%$ were below 20 years. Reason for majority of study subjects in the age group of 20 to 40 years could be it is economically productive age group, they are bread winners of the family. Similar findings were found by Lahariya et al., Lokesh et al., ${ }^{1,8}$ in an Indian study. Our study sample found slight male preponderance 54.8\% and females were $45.2 \%$. The reasons could possibly be in our country, males play a pivotal role in taking up responsibilities of family and are involved in meeting expenses of family. So any turbulence in their health, will affect family functioning and might have been brought earlier. This is not in line with Lahariya et al., study ${ }^{1}$ on Indian population.

$67.6 \%$ of study population were literates, may be due to better comprehension of illness, need for treatment, they might have approached psychiatric care. This is in line with Lokesh et al., study, Nishi et al., study ${ }^{8,10}$ which says patients with high level of education had more positive views about approaching psychiatrist. 
The sample consisted of $65.2 \%$ of unemployed people with $75.2 \%$ of low socio economic status. Reason for this may be that the sample was taken from a government hospital, which caters to people of low socio economic status, below poverty line. $57.2 \%$ of sample consisted of married subjects, $30.8 \%$ were unmarried, $5.2 \%$ are widowed and $6.8 \%$ were separated. Reason for this may be because of availability of care giving person in married population.

$32 \%$ of subjects had duration of illness 1 to 5 years. Majority of study subjects were schizophrenia spectrum disorders $(36.8 \%)$ followed by mood disorders $(22.8 \%)$ followed by substance abuse patients amounting to $19.6 \%$. This may be due to disorganised behaviour, disruption of daily activities might have prompted early consultation by schizophrenia and mood disorder patients than anxiety disorders.

$35.2 \%$ of patients have consulted faith healers as first contact of care, as helping agency for psychiatric problems, $19.6 \%$ have not taken any treatment from any facility before coming to our tertiary care centre (IMH). So taken together more than $50 \%$ of sample have not taken any professional help for their problems. Traditional faith healers are not professionals to manage psychiatric problems. They will just treat patients with spiritual methods and practices instead of pharmacological methods. Patients also because of their ignorance or stigma about psychiatric illness might have taken faith healer's help. $19.6 \%$ of study subjects have not taken any treatment, probably they might have thought that psychiatric problem resolves on its own. This delay in consultation leads to suffering making illness all the more refractory and affects outcome. These findings are in line with Indian studies. Many patients approached allopathic practitioners, general physicians, neurologists, ayurvedic, homeo, unani specialists and approached our hospital as last resort. Our study is in line with Lahariya et al., study ${ }^{1}$ which found $68.5 \%$ contacted faith healers as primary helping agency. Although indigenous systems like Ayurveda, unani play a minor role in management of psychiatric problems, there is a dire need to increase awareness among public to seek professional help. Longest delay in consultation as per our study was 13 years.

Even though lot of progress has happened in psychopharmacology, deinstitutionalization, it was found in our study that faith healers are the first care providers for majority of psychiatric patients [35.2\%]. Some of them are reverting back to faith healers when they were not satisfied with pharmacological treatment, however we did not find such things in our study. ${ }^{11}$ They are not approaching psychiatrist directly. 26.0\% approached general physician, $16.0 \%$ consulted private psychiatrist. Only $19.6 \%$ consulted tertiary care centre (IMH) as first help seeking agency. Even though 67.6\% of our sample has education they were taking a long pathway of care before consulting psychiatrists.

\section{Delay in duration of untreated illness across various psychiatric diagnosis}

Because of delay in first consultation with psychiatrists, duration of untreated illness was found to vary from 10 months to 11 years. On an average the duration of untreated illness of our sample was found to be 5.81 years. The average duration of illness for various diagnoses was highest for substance related disorders (10.6yrs), mental retardation, personality disorders (5.3yrs), schizophrenia (3.8yrs), mood disorders (3.22yrs), neurotic disorders (1.9yrs) and organic related disorders was 11 months (0.93yrs).

\section{Sociodemographic illness related variables and delay in first psychiatric consultation:}

Socio demographic correlates influencing first pathway of care before consulting psychiatrists as per our study were found to be aged 20 to 40 years, predominantly females, illiterates, unemployed, having monthly income less than 10,000 rupees, need to travel more than $100 \mathrm{kms}$ for reaching hospital. Illness related variable like having diagnosis of schizophrenia was a risk factor for approaching faith healers as first line of contact of treatment for care.

The choice of first consultation is usually based on several factors like affordability, cost, trust in treating doctor, past experiences shared from relatives, friends. Apart from all these issues environmental aspects like location of hospital, distance travelled, accessibility influences the choice of help seeking. In a country like ours, advice given by relatives, friends, social contacts play a very important role in decision making for selecting approach.

\section{Conclusion}

Majority of patients have been found to follow indirect pathway of psychiatric care approaching faith healers, alternative systems of medicine, general practitioners and finally psychiatrists. $28.4 \%$ of study sample have not consulted any doctor for their psychiatric problem out of which $8.8 \%$ consulted faith healers. Average delay in first psychiatric consultation as shown by duration of untreated illness as per our study was found to be $5.81 \mathrm{yrs}$.

Reasons for delay in first psychiatric consultation was found to be financial limitations, stigma, ignorance on part of family members. Socio demographic risk factors associated with delay in psychiatric consultation was found to be age 20 to $40 \mathrm{yrs}$, female gender, being illiterate, unemployment, long travel distance to hospital, income less than 10,000 rupees and diagnosis of schizophrenia.

\section{Limitations of the Study}

1. Our study was conducted at a tertiary care centre. A study done in general hospital would have given different results. 
2. Our sample was collected in the out patient department on preferred days. Collection of sample on all days in a week would have yielded a different sample containing heterogenous diagnoses.

3. Patient groups in our study were of different diagnoses, this might have influenced results.

\section{Implications of our study}

Patients with mental illness vary in their help seeking behavior. With reference to their first care providers and time to reach psychiatrist, they follow a long pathway of care for addressing their mental health problems. It is important to sensitize non psychiatrists, general practitioners about these issues for development of effective referral mechanism.

\section{Conflict of Interest}

None.

\section{Source of Funding}

None.

\section{References}

1. Lahariya C, Singhal S, Gupta S, Mishra A. Pathway of care among psychiatric patients attending a mental health institution in central India. Indian J Psychiatry. 2010;52(4):333-8.

2. Olfson M, Kessler RC, Berglund PA, Lin E. Psychiatric disorder onset and first treatment contact in the United States and Ontario. Am J Psychiatry. 1998;155(10):1415-22.

3. Chadda RK, Agarwal V, Singh MC, Raheja D. Help seeking behaviour of psychiatric patients before seeking care at a mental hospital. Int J Soc Psychiatry. 2001;47(4):71-8.
4. Weiss MG, Sharma SD, Gaur RK, Sharma JS, Desai A, Doongaji DR et al. Traditional concepts of mental disorder among Indian psychiatric patients: preliminary report of work in progress. Soc Sci Med. 1986;23(4):379-86.

5. Raguram R, Venkateswaran A, Ramakrishna J, Weiss MG. Traditional community resources for mental health: a report of temple healing from India. $B M J$. 2002;325(7354):38-40.

6. Janakiramaiah N, Badrinath B, Channabasavanna SM, Kaliaperumal VG. Dealing with deviant behaviour. Indian J Psychiatry 1979;21:206-10.

7. Chandrashekar H, Prashanth NR, Naveenkumar C, Kasthuri P. Innovations in Psychiatry: Ambulatory services for the mentally ill. Indian J Psychiatry. 2009;51(3):169-70.

8. Kumar L, Pavan Kumar Reddy CM, Sateesh Babu R. Delay in first psychiatric consultation and its reasons. AP J Psychol Med 2011;12(2): 79-83.

9. Gater R, Jordanova V, Maric N, Alikaj V, Bajs M, Cavic $\mathrm{T}$ et al. Pathways to psychiatric care in Eastern Europe. $\mathrm{Br}$ J Psychiatry. 2005;186:529-35.

10. Nishii H, Yamazawa R, Shimodera S, Suzuki M, Hasegawa T, Mizuno M. Clinical and social determinants of a longer duration of untreated psychosis of schizophrenia in a Japanese population. Early Interv Psychiatry. 2010;4(2):182-8. doi: 10.1111/j.17517893.2010.00179.x. PMID: 20536975.

11. Jain N, Gautam S, Jain S, Gupta ID, Batra L, Sharma $\mathrm{R}$ et al. Pathway to psychiatric care in a tertiary mental health facility in Jaipur, India. Asian $J$ Psychiatr. 2012;5(4):303-8. doi: 10.1016/j.ajp.2012.04.003.

How to cite this article: Sreevaram DM, Kumar MV, Rao SSS. A study of pathway of care among persons with mental illness attending a tertiary care centre in Hyderabad. Telangana J Psychiatry. 2020;6(2):137-142. 